\title{
Caregiver feeding styles and their effect on behaviour and activity of a cohort of preschool children in 4 selected schools in the Colombo District of Sri Lanka
}

\author{
*G U N Dias ${ }^{1}$, P K T K Panduwawala ${ }^{1}$, B L R Posonmali ${ }^{1}$, H D Ranaweera ${ }^{1}$, S M A N De Alwis ${ }^{1}$, S \\ Prathapan $^{2}$, G Liyanage ${ }^{3}$
}

Sri Lanka Journal of Child Health, 2018; 47: 215-218

\begin{abstract}
Background: Parental feeding styles (authoritative, authoritarian, indulgent and uninvolved) are varied. Some styles may have adverse effects on child behaviour. In Sri Lanka, we do not have information on parental feeding patterns.
\end{abstract}

Objectives: To describe caregiver feeding styles in 4 selected schools in the Colombo District of Sri Lanka and to investigate the relationship between caregiver feeding styles and child behaviour.

Method: This was a cross sectional survey based on validated questionnaires (Child behaviour questionnaire and Caregiver's feeding styles questionnaire). Main caregivers of preschool children between 3-5 years were recruited.

Results: Most (82\%) caregivers employ authoritarian feeding styles with more rules and control but less responsive to child's needs. Authoritative behaviour exhibit better child behaviour compared to other types of feeding styles.

Conclusions: In this study in 4 selected schools, $82 \%$ caregivers employed authoritarian feeding styles with less response to child's needs. Further, parents with authoritative feeding style exhibited better child behaviour compared to other feeding styles.

DOI: http://dx.doi.org/10.4038/sljch.v47i3.8541

\footnotetext{
${ }^{1}$ Medical Student, ${ }^{2}$ Senior Lecturer Department of Community Medicine, ${ }^{3}$ Senior Lecturer, Department of Paediatrics, Faculty of Medical Sciences, University of Sri Jayewardenepura, Sri Lanka

*Correspondence: dias.uvini@gmail.com

(Received 31 July 2017: Accepted after revision on

15 September 2017)

The authors declare that there are no conflicts of interest

Personal funding was used for the project.

Open Access Article published under the Creative

Commons Attribution CC-BY (c) (P)
}

(Key words: Feeding styles, behaviour, preschool, caregiver, demandingness, authoritative, indulgent authoritarian)

\section{Background}

Parental feeding styles adapted from typological approach to parenting have been developed by Hughes et $\mathrm{al}^{1}$. These feeding styles are characterized by demandingness (parental control over feeding with clear expectations on food consumption) and responsiveness (acceptance of child's needs) ${ }^{1}$. According to this, there are four types of feeding patterns. "Authoritative" pattern is associated with a high level of demandingness and high responsiveness. "Authoritarian" pattern is having high demandingness but lower responsiveness with rules but giving less priority to child's cues. "Indulgent" pattern executes more responsiveness but less rules and control. "Uninvolved" pattern is associated with both low demandingness and low responsiveness ${ }^{1}$.

We could not find any studies investigating parental feeding styles in Sri Lanka. However, there are a few studies published on parental feeding styles elsewhere ${ }^{2,3,4}$. An authoritative parenting style is generally associated with the most positive child outcomes, such as higher school performance ${ }^{4,5}$. Preschool age is the most important period during which emotional and cognitive development occur. There is a dearth of data in the world literature on how parental feeding styles affect child behaviour patterns. We hypothesized that the parental feeding style may have an impact on the behaviour and activity of the preschool child.

\section{Objectives}

To describe caregiver feeding styles in 4 selected schools in the Colombo District of Sri Lanka and to investigate the relationship between caregiver feeding styles and child behaviour.

\section{Method}

Ethics committee of the Faculty of Medical Sciences, University of Sri Jayewardenepura approved this 
study. Four schools from the Dehiwala Divisional Secretariat in the Colombo District, affiliated to international schools were chosen with the aim of including the higher income category. Convenient cluster sampling was done to recruit children between 3-5 years of age in each school. Exclusion criteria were children who were on long term follow up for chronic diseases, learning difficulties and physical disabilities. However, data were collected from those caregivers and discarded later.

Data were collected using three self-administered questionnaires. A pre-piloted questionnaire collected demographic data. Caregivers feeding styles questionnaire (CFSQ) was used to assess feeding styles among caregivers ${ }^{6}$. The CFSQ measures the overall feeding pattern of parents based on dimensions of demandingness and responsiveness. The two dimensions are derived through 7 childcentred and 12 parent centred feeding directives measured on a 5-point Likert scale (ranging from never to always). Child-centred feeding directives are those that promote child autonomy (e.g. reasoning, complimenting, and helping the child to eat). Parentcentred feeding directives attempt to control children's eating through external pressure (e.g., demands, threats, and reward contingencies). Children's behaviour questionnaire-short form (CBQ$\mathrm{SF}$ ) was used to assess behavioural response of child $^{7}$. It has 94 items that assess 15 aspects of child temperament. It is rated with a Likert scale of 1-7. It included an option to respond as not applicable when a particular situation is not experienced with the child. All three questionnaires were in the English language.

\section{Statistical analysis}

All statistical analyses were performed using the SPSS version 16.0. Data retrieved from the demographic portion of the study were reported in percentages and tables. The Mann Whitney $U$ test was used to compare differences between caregivers feeding pattern and behavioural response of children. Pearson's correlation test was used to measure the strength of association.

\section{Results}

Final sample consisted of two hundred preschool children. A parent was the main caregiver in $96 \%$ and a member of the extended family was the main caregiver in 4\%. Response rate was $89 \%(205 / 230)$. Three children ( 2 with learning difficulties and 1 with physical disability) were excluded. Two incomplete questionnaires were not taken for analysis. The profile of the caregiver is shown in Table 1.
Table 1: Profile of the caregiver $(n=200)$

\begin{tabular}{|c|c|}
\hline Characteristic & No. (\%) \\
\hline $\begin{array}{l}\text { Age group (years) } \\
20-29 \\
30-39 \\
>40\end{array}$ & $\begin{array}{c}36(18) \\
122(61) \\
42(21)\end{array}$ \\
\hline $\begin{array}{l}\text { Gender } \\
\text { Females } \\
\text { Males }\end{array}$ & $\begin{array}{c}190(95) \\
10(05)\end{array}$ \\
\hline $\begin{array}{l}\text { Educational level of parents } \\
\text { Ordinary Level or below } \\
\text { Completed Advanced level } \\
\text { University and higher }\end{array}$ & $\begin{array}{l}18(09) \\
84(42) \\
98(49)\end{array}$ \\
\hline $\begin{array}{l}\text { Employment } \\
\text { Employed } \\
\text { Unemployed }\end{array}$ & $\begin{array}{c}148(74) \\
52(26)\end{array}$ \\
\hline $\begin{array}{l}\text { Number of children } \\
\text { One child } \\
\text { Two children or more }\end{array}$ & $\begin{array}{r}66(33) \\
134(67) \\
\end{array}$ \\
\hline $\begin{array}{l}\text { Race } \\
\text { Sinhalese } \\
\text { Tamils } \\
\text { Moor } \\
\text { Others }\end{array}$ & $\begin{array}{l}86(43) \\
46(23) \\
56(28) \\
12(06)\end{array}$ \\
\hline
\end{tabular}

Age distribution of the main caregiver ranged from 24 to 50 years. Majority of the families had 2 children and index child was the first child in $55 \%$. Mean age of the children was 4.25 years.

\section{Demandingness and responsiveness}

Cut off value for demandingness and responsiveness were taken as 2.8 and 1.16 respectively ${ }^{8}$. Most of the caregivers were above the cut off level for demandingness $(93 \%)$ and below the cut off for responsiveness (90\%) (Table 2).

Table 2: Demandingness and responsiveness score

\begin{tabular}{|l|c|c|}
\hline & Demandingness & Responsiveness \\
\hline Mean (SD) & $3.36(0.35)$ & $1.01(0.13)$ \\
\hline Median & $3.36(0.35)$ & $1.02(0.13)$ \\
\hline Range & $2.4-4.11$ & $0.61-1.28$ \\
\hline
\end{tabular}

\section{Feeding styles and child behaviour}

Majority (82\%) of caregivers were practising an authoritarian feeding style. Authoritative and uninvolved feeding styles were $11 \%$ and $7 \%$ respectively. Mann-Whitney $U$ test showed a statistically significant difference $(p=0.017)$ in children's behaviour score between authoritative (median: 3.6061) and non-authoritative (median: 3.9192) feeding styles. Pearson correlation analysis was done to investigate the association between child behaviour and demandingness and responsiveness of caregiver. It demonstrated a negative low correlation 
for demandingness $(\mathrm{r}=-0.07, \mathrm{p}=0.484)$ and responsiveness $(r=-0.106, p=0.293)$.

\section{Effect of parent characteristics on child behaviour and feeding styles}

Children's behaviour score and parenting styles were compared with educational level and employment. Parents who were employed, scored a higher score for demandingness $(\mathrm{p}=0.001)$ and responsiveness $(p=0.019)$. However, educational level did not show an association to either demandingness $(\mathrm{p}=0.949)$ or responsiveness $(\mathrm{p}=0.396)$. Moreover, CBQ-SF score had no relationship to educational level $(\mathrm{p}=0.18)$ or employment status $(p=0.736)$.

\section{Discussion}

This study examined aspects of feeding practices which have not been previously studied in the Sri Lankan population. Data obtained from the questionnaires were all self-reported and the response rate of the study was relatively high. This study describes four types of caregivers' feeding styles (authoritative, authoritarian, indulgent and uninvolved) from a socio-demographic and child behaviour perspective. The majority of the studies that have evaluated feeding styles had been carried out in developed countries and a variety of protocols have been used but there is hardly any information available on feeding styles in Asian countries.

In this study, the majority had authoritarian feeding styles with parental control and rules over child food intake without adequate warmth, acceptance and recognition as a response to needs of the child. This is definitely higher when compared to results of many other studies ${ }^{1,9,10}$. Indulgent feeding style where parents would let the children eat whatever they want was not identified among our study subjects. Most likely reason for this finding could be that our sample having parents with higher socioeconomic background and these children are mostly supervised.

Although there is a dearth of data on feeding styles on preschool child behaviour and activity, it has been shown that authoritative parenting style is generally associated with the most positive child outcomes, such as higher school performance ${ }^{4,5}$. In our sample a low percentage demonstrated authoritative behavior. More importantly, in our study, favourable child behaviour was found with parents practising authoritative feeding styles when compared to other feeding patterns.

Feeding style has other implications on nutrition. In Vietnam, non-responsive feeding was associated with food rejection ${ }^{11}$. A study in Malawi revealed that excessive control of feeding behaviour was negatively associated with the acceptance of food by the child ${ }^{12}$. Food acceptance behaviour was not investigated in our study and future studies are warranted to evaluate this.

Many might think that unemployed mothers would take care of the child better than employed mothers. Unemployed mothers are at most times experiencing a load of household chores and settling arguments between siblings etc. On the other hand, employed mothers are multitasking and they manage their time with difficulty. Therefore, there does not seem to be much difference in stressors between the two groups. This could be the reason why we did not find a difference in child behaviour between employed and unemployed mothers. This statement was further supported by a recent research conducted in $\mathrm{UK}^{13}$. It reported that maternal employment during early years does not adversely affect socio-emotional behaviour of the child. However, in our study better scores for demandingness and responsiveness were seen among employed mothers. Child being cared for by several caretakers would have led to less stress on the main caregiver leading to good practices of feeding.

As a limitation of this cross-sectional study with selfadministered questionnaire, the results were dependent on the reporting of the caregiver. Absence of cultural validation of the questionnaire is another limitation. Moreover, not being able to do a comprehensive nutritional assessment of the children was another limitation. With more longitudinal studies on feeding styles and their relationship to child behaviour, we could emphasize acceptable feeding patterns that have positive effects on child behaviour.

\section{Conclusions}

In this study in 4 selected schools, $82 \%$ of our caregivers employed authoritarian feeding styles with less response to child's needs. Further, parents with authoritative feeding style exhibited better child behaviour compared to other feeding styles.

\section{References}

1. Hughes SO, Power TG, Orlet Fisher J, Mueller S, Nicklas TA. Revisiting a neglected construct: parenting styles in a child-feeding context. Appetite 2005; 44(1):83-92 https://doi.org/10.1016/j.appet.2004.08.007 PMid: 15604035 
2. Huang S, Parks EP, Kumanyika SK, Grier SA, Shults J, Stallings VA et al. Childfeeding practices among Chinese-American and Non-Hispanic White caregivers. Appetite 2012; 58(3): 922-7. doi:10.1016/j.appet.2012.02.008. https://doi.org/10.1016/j.appet.2012.02.008 PMid: 22343192 PMCid: PMC3340438

3. Hughes SO, Anderson CB, Power TG, Micheli N, Jaramillo S, Nicklas TA. Measuring feeding in low-income AfricanAmerican and Hispanic parents. Appetite 2006; 46(2):215-23.

https://doi.org/10.1016/j.appet.2006.01.002 PMid: 16504340

4. Johnson R, Welk G, Saint-Maurice PF, Ihmels M. Parenting styles and home obesogenic environments. International Journal of Environmental Research and Public Health 2012; 9(4):1411-26.

https://doi.org/10.3390/ijerph9041411

PMid: 22690202 PMCid: PMC3366620

5. Maccoby E, Martin J. Socialization in the context of the family: parent-child interaction. Handbook of Child Psychology. $1-101$.

6. Hughes SO, Cross MB, Hennessy E, Tovar A, Economos CD, Power TG. Caregiver's feeding styles questionnaire: Establishing cutoff points. Appetite 2012; 58(1): 393-5. https://doi.org/10.1016/j.appet.2011.11.011 PMid: 22119478 PMCid: PMC3268070

7. de la Osa N, Granero R, Penelo E, Domenech JM, Ezpeleta L. The short and very short forms of the Children's Behaviour Questionnaire in a community sample of preschoolers. Assessment 2014; 21(4): 463-76.

https://doi.org/10.1177/1073191113508809

PMid: 24235176

8. Darling N, Steinberg L. Parenting style as context: an integrative model. Psychological Bulletin 1993; 113(3): 487-96. https://doi.org/10.1037/00332909.113.3.487
9. Hoerr S, Hughes SO, Fisher JO, Theresa AN, Liu Y, Shewchuk RM. Associations among parental feeding styles and children's food intake in families with limited incomes. International Journal of Behavioral Nutrition and Physical Activity 2009; 6:55. https://doi.org/10.1186/1479-5868-6-55 PMid: 19678947 PMCid: PMC2739505

10. Tovar A, Hennessy E, Pirie A, Must A, Gute DM, Hyatt RR et al. Feeding styles and child weight status among recent immigrant mother-child dyads. Appetite 2005; 44(1):83-92.

11. Ha PB, Bentley ME, Pachón H, Sripaipan T, Caulfield LE, Marsh DR, et al. Caregiver styles of feeding and child acceptance of food in rural Vietnam. Food and Nutrition Bulletin 2002; 23(4Suppl):95-100.

PMid: 12503237

12. Flax VL, Mäkinen S, Ashorn U, Cheung YB, Maleta K, Ashorn P, et al. Responsive feeding and child interest in food vary when rural Malawian children are fed lipid-based nutrient supplements or local complementary food. Maternal and Child Nutrition 2013; 9(3):369-80. https://doi.org/10.1111/j.17408709.2011.003 77.x

PMid: 22118293

13. McMunn A, Kelly Y, Cable N, Bartley M. Maternal employment and child socioemotional behaviour in the UK: longitudinal evidence from the UK Millennium Cohort Study. Journal of Epidemiology and Community Health 2012; 66(7):19. https://doi.org/10.1136/jech.2010.109553 PMid: 21224241 